José Florencio F. Lapeña, Jr. MA, MD

Department of Otorhinolaryngology College of Medicine, University of the Philippines Manila, Philippines

Department of Otorhinolaryngology Head and Neck Surgery

East Avenue Medical Center, Diliman

Quezon City, Philippines

\section{Open Access: DOAJ and Plan S, Digitization and Disruption}

\author{
"Those with access to these resources - students, librarians, scientists - \\ you have been given a privilege. You get to feed at this banquet of knowledge \\ while the rest of the world is locked out. But you need not - indeed, morally, \\ you cannot - keep this privilege for yourselves. You have a duty to share it \\ with the world." \\ - Aaron Swartz' (who killed himself at the age of 26, \\ facing a felony conviction and prison sentence for \\ downloading millions of academic journal articles)
}

The Philippine Journal of Otolaryngology Head and Neck Surgery was accepted into the Directory of Open Access Journals (DOAJ) on October 9, 2019. The DOAJ is "a communitycurated online directory that indexes and provides access to high quality, open access, peerreviewed journals" ${ }^{\prime 2}$ and is often cited as a source of quality open access journals in research and scholarly publishing circles that has been considered a sort of "whitelist" as opposed to the now-defunct Beall's (black) Lists. ${ }^{3}$

As of this writing, the DOAJ includes 13,912 journals with 10,983 searchable at article level, from 130 countries with a total of 4,410,788 articles. ${ }^{2}$ Our article metadata is automatically supplied to, and all our articles are searchable on DOAJ. Because it is OpenURL compliant, once an article is on DOAJ, it is automatically harvestable. This is important for increasing the visibility of our journal, as there are more than 900,000 page views and 300,000 unique visitors a month to DOAJ from all over the world. ${ }^{2}$ Moreover, many aggregators, databases, libraries, publishers and search portals (e.g. Scopus, Serial Solutions and EBSCO) collect DOAJ free metadata and include it in their products. The DOAJ is also Open Archives Initiative (OAI) compliant, and once an article is in DOAJ, it is automatically linkable. ${ }^{4}$

Being indexed in DOAJ affirms that we are a legitimate open access journal, and enhances our compliance with Plan S. ${ }^{5}$ The Plan S initiative for Open Access publishing launched in September 2018 requires that from 2021, "all scholarly publications on the results from research funded by public or private grants provided by national, regional, and international research councils and funding bodies, must be published in Open Access Journals, on Open Access Platforms, or made immediately available through Open Access Repositories without embargo." ${ }^{\prime 5}$ Such open access journals must be listed in DOAJ and identified as Plan S compliant.

There are mixed reactions to Plan S. A recent editorial observes that subscription and hybrid journals (including such major highly-reputable journals as the New England Journal of Medicine, $J A M A$, Science and Nature) will be excluded, ${ }^{6}$ quoting the COAlition $S$ argument that "there is no 
valid reason to maintain any kind of subscription-based business model for scientific publishing in the digital world." ${ }^{\prime \prime} \mathrm{As}$ Gee and Talley put it, "will the rise of open access journals spell the end of the subscription model?"6

If full open access will be unsustainable for such a leading hybrid medical journal as the Medical Journal of Australia, ${ }^{6}$ what will happen to the many smaller, low- and middle-income country (southern) journals that cannot sustain a fully open-access model? For instance, challenges facing Philippine journals have been previously described. ${ }^{7}$

According to Tecson-Mendoza, "these challenges relate to (1) the proliferation of journals and related problems, such as competition for papers and sub-par journals; (2) journal funding and operation; (3) getting listed or accredited in major citation databases; (4) competition for papers; (5) reaching a wider and bigger readership and paper contribution from outside the country; and (6) meeting international standards for academic journal publications."7 Her 2015 study listed 777 Philippine scholarly journals, of which eight were listed in both the (then) Thomson Reuters (TR) and Scopus master lists, while an additional eight were listed in TR alone and a further twelve were listed in Scopus alone.? To date, there are 11,207 confirmed Philippine periodicals listed on the International Standard Serial Number (ISSN) Portal, ${ }_{1}^{8}$ but these include non-scientific and non-scholarly publications like magazines, newsletters, song hits, and annual reports. What does the future have in store for small scientific publications from the global south?

I previously shared my insights from the Asia Pacific Association of Medical Journal Editors (APAME) 2019 Convention (http://apame2019. whocc.org.cn) on the World Association of Medical Editors (WAME) Newsletter, a private Listserve for WAME members only. ${ }^{9}$ These reflections on transformation pressures journals are experiencing were the subject of long and meaningful conversations with the editor of the Philippine Journal of Pathology, Dr. Amado Tandoc III during the APAME 2019 Convention in Xi'an China from September 3-5, 2019. Here are three main points:

1. the real need for and possibility of joining forces- for instance, the Journal of the ASEAN Federation of Endocrinology Societies (JAFES) currently based in the Philippines has fully absorbed previous national endocrinology journals of Malaysia and the Philippines, which have ceased to exist. While this merger has resulted in a much stronger regional journal, it would be worthwhile to consider featuring the logos and linking the archives of the discontinued journals on the JAFES website. Should the Philippine Journal of Otolaryngology Head and Neck Surgery consider exploring a similar model for the ASEAN
Otorhinolaryngological - Head and Neck Federation? Or should individual specialty journals in the Philippines merge under a unified Philippine Medical Association Journal or the National Health Science Journal Acta Medica Philippina? Such mergers would dramatically increase the pool of authors, reviewers and editors and provide a sufficient number of higher-quality articles to publish monthly (or even fortnightly) and ensure indexing in MEDLINE (PubMed).

2. the migration from cover-to-cover traditional journals (contents, editorial, sections, etc.) to publishing platforms (e.g. should learned Philippine societies and institutions consider establishing a single platform instead of trying to sustain their individual journals)? Although many scholarly Philippine journals have a long and respectable history, a majority were established after 2000, possibly reflecting compliance with requirements of the Commission on Higher Education (CHED) for increased research publications. Many universities, constituent colleges, hospitals, and even academic and clinical departments strove to start their own journals. The resulting journal population explosion could hardly be sustained by the same pool of contributors and reviewers.

In our field for example, faculty members of departments of otorhinolaryngology who submitted papers to their departmental journals were unaware that simultaneously submitting these manuscripts to their hospital and/or university journals was a form of misconduct. Moreover, they were not happy when our specialty journal refused to publish their papers as this would constitute duplicate publication. The problem stemmed from their being required to submit papers for publication in department, hospital and/or university journals instead of crediting their submissions to our pre-existing specialty journal. This escalated the tension on all sides, to the detriment of the new journals (some department journals ceased publication after one or two issues) and authors (whose articles in these defunct journals are effectively lost).

The older specialty journals are also suffering from the increased number of players with many failing to publish their usual number of issues or to publish them on time. But how many (if any at all) of these journals (especially specialty journals) would agree to yield to a merger with others (necessitating the end of their individual journal)? Would a common platform (rather than a common journal) provide a solution?

3. more radically, the individual journal as we know it today (including the big northern journals) will cease to exist- as individual $\mathrm{OA}$ articles (including preprints) and open (including post-publication) review become freely available and accessible to all. However proud 


\section{EDITORIAL}

editors may be of the journals they design and develop from cover to cover, with all the special sections and touches that make their "babies" unique, readers access and download individual articles rather than entire journals. A similar fate befell the music industry a decade ago. From the heyday of vinyl (33 and 78 rpm long-playing albums and 45 rpm singles) and 8-tracks, to cassettes, then compact disks (CD's) and videos, the US recorded music industry was down 63\% in 2009 from its peak in the late 70's, and down 45\% from where it was in $1973 .{ }^{10}$ In 2011, DeGusta observed that "somewhat unsurprisingly, the recording industry makes almost all their money from full-length albums" but "equally unsurprising, no one is buying full albums anymore," concluding that "digital really does appear to have brought about the era of the single. ${ }^{10}$ As McDowell opines, "In the end, the digital transforms not only the ability to disrupt standard publishing practices but instead it has already disrupted and continues to break these practices open for consideration and transformation."11

Where to then, scientific journals? Without endorsing either, will Sci-Hub (https://sci-hub.se) be to scholarly publishing what Spotify (https://www.spotify.com) is to the music industry? A sobering thought that behooves action.

\section{REFERENCES}

1. Swartz A. Guerilla Open Access Manifesto. 2008 July; Eremo, Italy. [cited 2019 November 11] Available from https://archive.org/stream/GuerillaOpenAccessManifesto/Goamjuly2008_djvu. txt.

2. Directory of Open Access Journals. [Internet]. [cited 2019 November 9] Available from https:// doaj.org.

3. Beall J. Beall's list of predatory journals and publishers 2016. Scholarly Open Access. Formerly available at https://scholarlyoa.com/2017/01/03/bealls-list-of-predatory-publishers-2017/; [cited 2019 October 3] Available from https://beallslist.weebly.com.

4. Open Archives Initiative. [Internet] New York: Cornell University Library Information Technology; 2019. [cited 2019 October 9] Available from https://www.openarchives.org.

5. Coalition S. Plan S: Principles and Implementation, Part I. The Plan S Principles. [Internet] Brussels: Science Europe; 2019. [cited 2019 November 9] Available from https://www. coalition-s.org/principles-and-implementation/.

6. Gee $C E$, Talley N. Disrupting medical publishing and the future of medical journals: a personal view. Med J Aust. 2019 Aug;211(4):167-168. DOI: 10.5694/mja2.50281 DOI:10.5694/mja2.50281 PMID:31422578.

7. Tecson-Mendoza EM. Scientific and academic journals in the Philippines: status and challenges. SciEd 2015;2(2):73-78. DOI: https://doi.org/10.6087/kcse.47.
8. International Standard Serial Number International Centre (ISSN IC), ISSN Portal: The Global Index for Continuing Resources. [Internet] Paris: International Centre for the Registration of Serial Publications; 2019. [cited 2019 November 10]. Available from: https://portal.issn.org/? q=api\%2Fsearch\&search\%5B0\%5D=MUST\%3Dcountry\%3DPHL\&search\%5B1\%5D=MUST\% 3Drecord\%3DRegister\&search\%5B2\%5D=MUST\%3Dmedium\%3Dco\%2Cta\%2Ccr\&size =10\&search_id=3090592\&currentpage $=41$.

9. Winker M, (editor). Publishing: Insights from the Asia Pacific Association of Medical Editors (APAME) 2019 conference. [WAME listserve] WAME Newsletter 69, October 21, 2019: Apply now for grants supporting the use of Research4Life; Challenges for young researchers in Africa; What are the health consequences of predatory journals? (Private Listserve for WAME members only).

10. DeGusta M. The REAL Death of the Music Industry. Business Insider, February 19, 2011. [Cited 2019 November 9] Available from https://www.businessinsider.com/these-charts-explain-thereal-death-of-the-music-industry-2011-2.

11. McDowell ZJ. Disrupting Academic Publishing: Questions of Access in a Digital Environment Media Practice and Education. 2018 May;19(1)52-67. DOI: 10.1080/14682753.2017.1362173. 